\title{
A INTEGRAÇÃO AÉREA DO NORTE PARANAENSE NO MERCOSUL
}

Flademir Candido da Silva*

SUMÁRIO: 1. Introdução. 2. Convenção de Chicago e Céus Abertos. 3. O Modclo Comunitário. 4.Acordo de Fortalcza. 5. Aviação Civil no Norte do Paraná. 6. Conclusão. 7. Bibliografia.

SUMMARY.1.Introducion. 2. Chicago's Convention and Open Skies. 3. Comunitary Model. 4. Agreement of Fortaleza. 5. Civil Aviation in North Atea of Paraná. 6. Conclusion. 7. Bibliography.

SUMARIO: 1. Introducion. 2. La Convención de Chicago y los Cielos Abiertos. 3. O Modelo Comunitario. 4. Acuerdo de Fortaleza. 5. Aviación civil en Área Norte de Paraná. 6. Conclusión. 7. Brbliografia.

RESUMO: AO analisar o potencial econômico do Mercosul e a necessidade imperiosa de aumentar as conexôes para obtençấo de vantagens no processo de integração, considera o potencial estratégico da posição geográfica da Região Norte do Paraná, argumeata que a solução local está no transporte aéreo. Entretanto, a alternativa não depende, exclusivamente, da infra-estrutura aeroportuária do local, mas de aspectos legais inerentes ao Dircito da Integração, Direito Aeronáutico e, também, da política de transporte aéreo. Destaque, na questão é o Acordo de Fortaleza, um pacto entre os PaísesPartes do Mercosul e associados (Chile, Bolivia e Peru), um importante diploma multilateral, que indica um novo marco para a estruturação da Aviação Civil na América do Sul.

ABSTRACT: When analyzing the economic potential of Mercosul and the imperious necessity of increasing the ways for obtaining of advantages in the integration process, it considers the strategic potential of the geographical position of the North Area of Parana, it argues that the solution is air

"Mestrando em Direto Negocial pela Uniwersidade Estadual de Londrina. 
transport. However, this altenative it doesn't depend, exclusively, of the airport infrastructure of the place, but inherent legal aspects to the integration Law, Air Law and, also, of the air transport policy. Highlight, in the subject it is the Agreement of Fortaleza, an agreement among the Countryparts of Mercosul and associated (Chile, Bolivia and Peru), an important multilateral diploma, that indicates a new mark for the structuring of the Civil Aviation in South America.

RESUMEN: Cuando analizando el potencial económico de Mercosul y la necesidad imperiosa de aumentar las maneras por obtener de ventajas en la integración procesan, considera el potencial estratégico de la posición geográfica del Area Norte de Parana, defiende que la solución es transporte aéreo. Sin embargo, esta alternativa que no depende, exclusivamente, de la infraestructura del aeropuerto del lugar, pero aspectos legales inherentes a la Ley de la integración, to Derecho Aeronautico y, también, de la politica de transporte aéreo. Resalte, en el asunto es el Acuerdo de Fortaleza, un acuerdo entre los Pásparte de Mercosul y asociado (Chile, Bolivia y Peru), un diploma multilateral importante, que indica una nueva marca para la estructuración de la Aviación Civil en América del Sur.

PALAVRAS-CHAVES: Direito Aeronáutico. Direito de Integração. Infraestrutura aeroportuára. Acordo de Fortaleza. Norte do Paraná. Mercosul. Aviaço Civil, aeronáutica. Políica de Transporte Aéreo.

KEY-WORDS: Air Law, Integration Law. Airport Infastructute. Agreenent of Fortaleza. North Area of Paraná. Mercosul. Civil Aviation. Aeronautics. Air Transport Policy.

PALABRAS-LLAVES: Derecho Acronautico. Derecho de la Integración. Infraestructura del aeropnerto. Acuerdo de Fortaleza. Area Nonte de Pananá, Mercosul. Aviación Civil. Aeronáutica. Politica de Transporte Acreo.

\section{Introdução}

Na Comunidade Andina assim como na União Européia, o pleno desenvolvimento dos transportes aflorou como uma preocupação central, pois não se concebe um processo integrador sem a locomoção eficiente dos fatores de produção: mercadorias, serviços ou pessoas. $O$ trans- 
porte é, portanto, um serviço responsável pela integração física do espaço geográfico e sua infra-estrutura é o meio para o desenvolvimento do livre comércio intra-regional, bem como para a inserção eficiente do bloco, no plano internacional.

O artigo $1^{\circ}$ do Tratado de Assunção prevê a coordenação de políticas setoriais de transporte e o seu anexo $\mathrm{V}$ estipula a constituição de 2 (dois) dos 11 (onze) subgrupos, especializados ao tema transporte: o subgrupo 5 (cinco) dedicado ao transporte terrestre e o subgrupo 6 (seis) ao transporte marítimo. Apesar desta preocupação com a integração física, ficou evidente um tratamento parcial da questão, pois os outros modais não foram contemplados nos subgrupos estabelecidos. Em 1992, levando em consideração a importância hidroviária da Bacia do Prata, corrigiram a exclusão do transporte fluvial e o Grupo Mercado Comum(GMC) encarregou o SGT 6 (transporte marítimo) de tratar, também, dos temas relativos ao transporte fluvial e assuntos portuários. Três anos após, houve uma reestruturação ${ }^{2}$ dos grupos de trabalho e fundiram os dois subgrupos anteriores no SGT 5 (transportes), que passou a tratar da integração física de forma geral, mas sem nenhuma menção ao transporte aéreo.

A contemplação do modal aéreo, no processo de integração, só começou a ocorrer a partir de dezembro de 1996, quando foi assinado, em Fortaleza, o Acordo sobre Serviço Aéreo Sub-Regional entre os PaísesPartes e Associados. Embora o Acordo de Fortaleza não seja resultante da atividade institucional do Mercosul, ele é reconhecido pela instituição, pois foi ratificado pelos mesmos Estados Partes e representa um marco na integração aérea da sub-região, merecendo ser analisado a luz das políticas aerocomerciais comunitárias e do Direito Aeronáutico do Mercosul. Este artigo apontará os principais elementos da análise, focalizando as conseqüências do Acordo de Fortaleza para a micro-região Norte do Paraná. sua estreita relaça com os temas vinculados ao transporte maritimo, e que transporte fluvial e aspectos portuários não são tratados em outros subgrupos de trabalho, O GRUPO MERCADO COMUM RESOLVE: Artigo 10 - Encarregar o SGT" 6 "Transporte Maritimo" de tratar dos temas relativos ào transporte fluvial e asssuntos pontuátios

¿Através da resoluçäo GMC $20 / 95$. 


\section{Convenção de Chicago e Céus Abertos}

A Convenção de Chicago de 1944 definiu o Acordo multilateral da Aviação Civil Internacional e estabeleceu a OACI (Organização Aviação Civil Internacional), constituindo a base normativa do principais princípios que regulam a atividade aérea internacional. $O$ Acordo de Chicago foi resultante de um grande esforço de conciliação no sentido da uniformização das regras e métodos a serem considerados no transporte aéreo internacional, e entre as suas diretrizes estão: a aviação civil deve desenvolver-se de forma segura e ordenada; os Estados podem negociar serviços aéreos internacionais, mediante o princípio da reciprocidade; e os serviços devem ser executados de forma eficaz e econômica. A Convenção enfatizou a soberania dos Estados e a necessidade dos acordos bilaterais como condição jurídica necessária para a exploração dos serviços aéreos internacionais.

Segundo o Dr. Expedito Albano da Silveira ${ }^{3}$, o sistema bilateral de transporte aéreo fundado na Convenção de Chicago está obsoleto, mas sobreviverá por algum tempo. Um novo ciclo já se formou com a Política de Céus Abertos, na qual o ente mercado regula o serviço aéreo ao invés dos Estados, nos modelos dos acordos bilaterais. Na globalização dos serviços, os Acordos Multilaterais Regionais constituiria uma etapa intermediária para um novo transporte aéreo internacional mais aberto, globalizado e eficiente. A Politica de Céus Abertos seria o objetivo e constitui, portanto, um conjunto de ações públicas e privadas, tendendo a eliminar os limites da oferta, da capacidade no âmbito dos serviços aéreos internacionais, relegando os vários aspectos regulatórios às força do mercado.

\section{Modelo Comunitário}

A Comunidade Andina (CAN) ${ }^{4}$ adotou uma série de normas comunitárias para facilitar a liberação dos diversos serviços de transporte entre seus países membros e contribuiu, dessa forma, para o crescimento do

\footnotetext{
SILVEIRA, Expedito Albano da. A Globalizaçăo os Acordos Bilaterais. SBDA: revista n 80 , Rio de Janeiro, 2000. Disponivel em: Khapp//www.sbda.org.br. Acesso em 10 jan. 2004.

Capitulo 12 do Acordo de Cartagena sobre a integracão fisica:

Articulo 104.- Los Páses Mierabros desarrollarán una acción conjunta para lograr un mejor aprovechamicnto del espacio físico, fortalecer la infraestructura y los servicios necesarios para el wance del proceso de integración económica de la Subregión. Esta acción se ejercerá principalmente en los campos de la energia, los transportes y las comunicaciones, y comprenderá las medidas necesarias a fin de facilitar el trafico tronterizo entre los Paises Miembros.
} 
comércio e fortalecimento da integração física do bloco. No modal aéreo, considerando que o direito de sobrevôo (1ำ liberdade $)^{5}$ e pouso técnico ( $2^{\circ}$ liberdade) foram consagrados com a Convenção de Chicago, através da Decisão 297 da CAN ${ }^{6}$, os Estados da comunidade passaram a integrar um regime especial de amplas facilidades estendendo os direitos de $3^{\circ}, 4^{\circ}, 5^{\circ}$ e $6^{\circ}$ liberdades em vôos regulares que se realizem dentro da sub-região, transladando: passageiros, carga ou correio. Foi estabelecida, portanto, uma política de Céus abertos na sub-região, que viabilizou a multiplicação de empresas beneficiadas com o livre acesso ao mercado comum, sem as restrições decorrentes dos acordos bilaterais. Desta forma, surgiram novas rotas, empresas e serviços para os usuários andinos.

Na União Européia, embora o Tratado de Roma de 1957 previsse a consecução de uma Política Comum de Transportes, no título IV (artigos 74 a 84), só após 1987, com o Ato Único Europeu, que um conjunto de medidas legislativas coordenadas estabeleceu uma consistente Política Comum Transporte, extensiva ao modal aéreo.

Segundo o Dr. Gualdino Rodrigues: são vários os motivos que explicam a inação das instituições comunitárias neste domínio. Em primeiro, a situação do transporte aéreo no espaço comunitário era igual à situação do transporte aéreo em todo o mundo; um modo de transporte espartilhado pelo regime bilateral e, assim, vedado à liberalização e a um mercado aberto. Também a dimensão geográfica da CEE, com 6 Estados fundadores, não propiciava políticas inovadoras e contra o sistema vigente mundialmente, a que acresce, ainda, a falta de vontade política dos Estados membros em modificarem este estado das coisas. A Comissão dava-se conta das dificuldades, que teria de enfrentar se quisesse desmantelar, no interior

\footnotetext{
'Classificação dos Direitos de Tráfego Aéreo ou Liberdades do Ar (Freedom of Air):

$1^{2}$ liberdade - o direito de sobrevoar o território de outro Estado sem pousar.

$2^{2}$ liberdade - o direito de pousar por motivos técnicos, tais como reabastecimento, pane ou força maior.

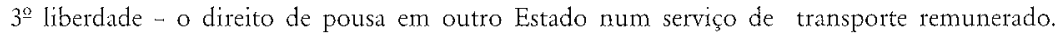

4 liberdade - o direito de decolar para o Estado de origem, num serviço de transporte remunerado.

5o liberdade - o direito de dar continuidade a um vôo, seguindo para um terceiro Estado, num serviço de transporte remunerado.

6o liberdade - o direito de conciliar as terceiras e quartas liberdade fazendo ponte com um terceiro Estado, no país de origem.

$7^{\circ}$ liberdade - o direito de transportar para um outro Estado, sem ter sair do estado de origem.

8o liberdade - o direito de transportar entre dois pontos interno de um Estado, num vôo proveniente do estado de origem. A oitava liberdade é denominada de "cabotagem consecutiva".

9․ liberdade - o direito de transportar entre dois pontos internos de um Estado, de forma independente ( sem provir do país de origem da empresa). O direito de nona liberdade é, também, denominado de cabotagem "autônoma".
}

"Aprovada en 16 de maio de 1991 pela Comissão do Acordo de Cartagena. 
da CEE, um mercado muito estruturado a nível mundial e que correspondia à expressão da soberania dos Estados sobre o seu espaço aéreo e garantia a defesa dos interesses e posições nacionais, de cada Estado e das suas transportadoras. (Rodrigues, 2003, p.207)

A liberalização do transporte aéreo europeu abrangeu a regulação dos seguintes aspectos: o acesso ao mercado; a capacidade e o exercício dos direitos de tráfego; o estabelecimento dos níveis e das condiçốes das tarifas aéreas; a aplicação das regras da concorrência ao transporte aéreo; e as políticas externas da União Européia. Foi criado o mercado interno europeu de transporte aéreo (Céu Único Europeu), de forma gradual, em três etapas. $\mathrm{O}$ acesso ao mercado comunitário de transporte aéreo unificado, permite a exploração dos serviços de cabotagem e a União Européia, após 2001, negocia os serviços aéreos em nome dos 15 Estados membros como um bloco, considerando que a Corte de Justiça declarou ilegais os acordos bilaterais de vários Estados membros, celebrados segundo a Convenção de Chicago.

\section{Acordo de Fortaleza}

O avanço no transporte aéreo na sub-região está fundamentado no Acordo de Fortaleza, que propõe um conjunto de normas que visam permitir e estimular a realização de serviços aéreos, em rotas diferentes das implementadas nos termos dos acordos bilaterais existentes. O Acordo foi assinado pelas autoridades aeronáuticas do Brasil, Argentina, Uruguai, Paraguai, Bolivia e Chile e está aberto a participação de outros Estados sul-americanos e do Caribe ${ }^{8}$.

Na questão de direitos de tráfego ou liberdades do ar, diferentemente do que ocorre no bloco andino e europeu, o Acordo de Fortaleza não prevê uma política de Céus Abertos na sub-região, pois não se cogita as concessões das liberdades liberais de tráfego e os avanços se resumem as $3^{\circ}$ e $4^{\circ}$ liberdades do ar, em rotas diversas das existentes nos Acordos bilaterais estabelecidos. As $5^{\circ}$ e $6^{\circ}$ liberdades aéreas necessitam da aprovação dos Estados envolvidos, e as $7^{\circ}, 8^{\circ}$ e $9^{\circ}$ liberdades (cabotagem) são inconcebíveis. Na União Européia a política aerocomercial comunitária fez com que os acordos bilaterais cedessem a uma nova distribuição do tráfego decorrente do Céu Único Europeu.

\footnotetext{
"Foi ratificado pelos Estados proponentes, mas houve atraso na ratificação da Argentina. No Brasil, o Acordo foi ratificado no pelo Decreto Presidencial de $\mathrm{n}^{\circ} 3.045$, de 05 de mato de 1999.

:O Peru aderiu em 2001 e a Venezuela e a Colombia tendem a participar. 
O artigo 18 do Acordo de Fortaleza prevê a revisão periódica do pacto com objetivo de eliminar, gradualmente, as restrições existentes e neste sentido, o Conselho de Autoridades Aeronáuticas do Acordo temse reunido todos os anos, estipulando metas para uma maior integração aérea sub-regional. Contudo, as decisões do Conselho carecem dos efeitos da supranacionalidade, sendo que as últimas reuniões têm sido marcadas pelo impasse entre as posições liberais chilenas e as conservadoras brasileiras. O Brasil não estabeleceu uma política aérea definitiva e suas companhias aéreas principais estão passando por uma grave crise financeira, enquanto que o Chile, com seu marco regulatório definido no setor, adota uma política de Céus Abertos e possui uma competitiva companhia aérea internacional ( LanChile), que está em condições de liderança com a abertura regional face ao estado financeiro de suas concorrentes regionais: VARIG, TAM e Aerolíneas Argentinas.

No dia 3 de dezembro de 2003 teve lugar, em Montevidéu, uma reunião do Conselho de Autoridades Aeronáutica para tratar de temas como: a nova forma de negociações aerocomercial adotada pela União Européia, a proposta de um novo acordo aéreo para os países integrantes da sub-região e as metas de aberturas estabelecidas pelo Conselho. As autoridades aeronáuticas brasileiras manifestaram que não estavam em condições de aplicar a fase três do Memorando de Santiago do Chile ${ }^{9}$, aprovado em 2001, que prevê uma liberação total da capacidade nas rotas do Convênio de Fortaleza, desde julho de 2003.

Segundo Carlos Rodrigues Brianza ${ }^{10}$, no Balanço de 2003 sobre a integração aérea:

\footnotetext{
"MEMORANDO DE SANTIAGO:

O conselho de Autoridades de Aviação Civil do Sistema de Transporte Áéreo Sub-regional, previsto no Acordo de Fortaleza, concluído em 17 de dezembro de 1996, reuniu-se nos dias 01 e 02 de março de 2001, em Santiago do Chile, oportunidade em que aprovou Memorando de Entendimento relativo ao Transporte Aéreo na Sub-região, cujas as principais decisões foram:

A partir de $1^{a}$ de julho de 2001, aumentar a capacidade acordada entre os Estados Membros bilateralmente em, pelo menos, 30\% para vôos regionais - $3^{\underline{0}}$ e $4^{\circ}$ liberdades, e eliminar as restrições existentes quanto aos pontos a operar dentro dos limites de seus territórios;

A partir de $1^{\underline{a}}$ de julho de 2002, aumentar a capacidade já ampliada conforme o item $1 \mathrm{em}$, pelo menos 50\%, e eliminar as restrições existentes quanto ao exerćcio dos direitos de $5^{\circ}$ e $6^{\circ}$ liberdades bilateralmente acordados, no âmbito intra-regional;

A partir de $1^{\underline{\underline{a}}}$ de julho de 2003 , liberalizar totalmente a capacidade e as freqüências acordadas nos respectivos Acordos bilaterais, no âmbito intra-regional.

O Memorando de Santiago foi assinado pelos Diretores de Aviação Civil do Brasil, Chile, Paraguai e Uruguai, aguardando-se a adesão da Argentina, da Bolívia e do Peru, também Partes Contratantes do Acordo de Fortaleza. ${ }^{10}$ BRIANZA, Carlos Rodrigues. Balance 2003.- Segunda Parte: la integración. AVIAGLOBAL: artigo, 30 dez. 2003. Disponivel em:〈htpp://www.aviaglobal.com〉. Acesso em 10 jan. 2004.
} 
El convenio de Fortaleza fue una "herramienta" promovida y creada en algún momento por quienes temían en ese momento una verdadera integración por via política o diplomática, mediante la inclusión del tema del transporte aéreo dentro del Mercosur o la Organización Mundial del ComercioY a la luz de los hechos, a través de dicho mecanismo no solo se logró el objetivo de demorar más de ocho años ese processo de integración en el sector aeronáutico, sino que al día de hoy, luego de la reciente Reunión del Consejo de Autoridades celebradas em Montevideo, quizás hasta estemos más lejos que en aquél 1996.

A posição sustentada pelo Brasil na reunião do Conselho de Autoridades Aeronáuticas do Convênio de Fortaleza, em Montevidéu, tem sido interpretada como um obstáculo para a integração aeronáutica regional, pois além de limitar os direitos de tráfego, o país não buscou avançar nos outros tópicos importantes para integração, como: segurança operacional, aeroportos regionais, capacitação de pessoal, certificação e outros temas que não possuem vínculo direto com os aspectos econômico decorrentes da crise das companhias aéreas. Ressaltando-se, porém, que o Brasil invocou a necessidade da elaboração de um diagnóstico prévio para os próximos avanços, o que na prática, protela a revisão do Convênio de Fortaleza e a prometida integração aeronáutica na subregião.

\section{Aviação Civil no Norte do Paraná}

Apesar da majoritária e procedente crítica à inércia brasileira em relação ao esperado avanço nos compromissos do Acordo de Fortaleza, alguns passos irreversiveis foram tomados no sentido da integração aérea; um bom exemplo da vontade integradora, está nos estudos para os aeroportos regionais. O Instituto de Aviação Civil ( IAC), órgão técnico planejador da política aeroportuária brasileira, elaborou, em maio de 1999, o louvável Estudo Básico para a Internacionalização de Aeroportos de Apoio à Aviação Sub-Regional no Mercosul. ${ }^{11}$ Um trabalho técnico que utilizou uma metodologia baseada no Método de Análise Hierárquica de Thomas Saaty para enumerar os aeroportos sujeitos a ser internacionalizados para atender ao novo mercado da aviação sub-regional

\footnotetext{
"INSTTUTO DE AVIACAO CVIL. Estudo basico para a internacionalização de Aeroportos de apoio à aviaça sub-regional no Mercosul. Rio de Janeiro: maio, 1999. 
do Mercosul. Foram analisados e hierarquizados cerca de 50 aeroportos dos Estados do Rio Grande do Sul, Santa Catarina, Paraná, São Paulo e Mato Grosso do Sul, em função: da proximidade com a fronteira; potencial sócio-econômico; previsão de demanda por transporte aéreo e infra-estrutura aeroportuária da cidade.

Foram feitas três classificações em função da distância com a fronteira, considerando que as novas rotas transversais seriam de 600 a 1000 $\mathrm{km}$ entre países do Mercosul. Quando foram hierarquizadas as cidades que situam-se num raio de até $300 \mathrm{Km}$ da fronteira, o Aeroporto de Maringá obteve a primeira colocação e Londrina não foi classificada, por distar fora da faixa (a $350 \mathrm{~km}$ ). Na segunda classificação, que considerou as cidades que situam-se até $400 \mathrm{Km}$ da fronteira, o Aeroporto de Londrina liderou com potencial muito alto para internacionalização e Maringá ficou em $4^{\circ}$ lugar. Já na terceira e última classificação, que considerou as cidades que situam-se no raio de ate $500 \mathrm{Km}$ da fronteira, o Aeroporto de Londrina, novamente, ficou na liderança e Maringá foi para o $5^{\underline{a}}$ lugar, em função da sua limitada infra-estrutura aeroportuária e do menor potencial de sua demanda para o transporte aéreo.

Entre as vantagens da infra-estrutura aeroportuária da cidade de Londrina estão:

- um terminal de passageiro moderno e amplo, com a capacidade para recebimento do triplo de sua demanda em 2003 ( cerca de 1 milhão de passageiros anuais);

- Serviço de Combate a Incêndio e bombeiros especializados na atividade de emergência aérea;

- equipamentos de navegação aérea sofisticados com previsão de instalação de ILS (Instrument Landing System), que favorecerá o pouso de aeronaves em condições mínimas de teto e visibilidade;

- uma pista resistente em projeto de ampliação, para viabilizar pouso de grandes aeronaves e cargueiros médios;

- e, ainda, a único serviço de controle responsável pelo trafego aéreo (TWR) abaixo do 5000 pés, em todo o Norte do Paraná, numa Área Terminal(TMA) que possui um raio de cerca de $100 \mathrm{Km}$, incluindo Maringá, no setor oeste e chegando próximo à Presidente Prudente, cidade do Sudoeste de São Paulo.

De acordo com o artigo 6 do Acordo de Fortaleza: "Para efeitos das rotas sub-regionais, considerar-se-ão como um único os aeroportos de 
um mesmo Estado situados dentro do limite de uma TMA,...". Aliás, não se justifica a existência de mais de um acroporto até entre as cidades próximas em Estados vizinhos, a exemplo do que ocorre na tríplice fronteira, que possui três aeroportos internacionais, num raio de cerca de 20 $\mathrm{km}$. O primeiro construído foi em Foz do Iguaçu, no Brasil; o segundo, em Cataratas, na Argentina; e o terceiro foi o Aeroporto Guarani, no Paraguai. Os três aeroportos deficitários pela baixa demanda, lembram à análise do Dr. Adyr da Silva, esta situação é um exemplo perverso da oportunidade perdida de cooperação, cuja grande potencialidade é mal utilizada. Os recursos investidos nas regiões fronteiras entre o Brasil e seus oito Estados vizinhos poderiam ser muito melhor aproveitados, caso houvesse uma estreita e bem planejada cooperação aeroportuária. Eles são um claro exemplo de desperdício a nível regional. ${ }^{12}$

O estudo do IAC evidenciou o alto potencial da Região Norte do Paraná para o transporte aéreo sub-regional ao considerar a possibilidade de internacionalização de dois aeroportos da micro-região. Não obstante, a evidente carência de um aeroporto internacional com um terminal de carga aérea, como pólo catalisador do desenvolvimento do Norte do Paraná; é questionável a viabilidade de dois aeroportos internacionais na região, numa distância próxima, em função do alto risco de desperdício resultante da divisão da demanda, considerando o custo operacional significativo para implementação de novas estruturas .

A participação alternativa do Aeroporto de Maringá no processo seria benéfica para região, caso houvesse o desenvolvimento da conexão intermodal entre as duas principais cidades da região, favorecendo a uma política de formação de metrópole no eixo entre as duas cidades. Uma estratégia de desenvolvimento regional que transcende a capacidade dos municípios e depende do apoio do Governo Estadual, que nos mandatos anteriores esteve muito preocupado com o embelezamento de

\footnotetext{
${ }^{12}$ Da Silva, 1991 , p. 165

12.3- APROVAR as seguintes diretrizes para o mercado regional (América do Sul);

3.1 A politica de designaça para o mercado regional (Anérica do Sul) sexá a de multidesignaça quando esta estiver prevista nos respectivos acordos sobre serviços aéreos.

3.2 Aeroportos domésticos poderäe ser utilizados no tráfego regional internacional, atendidos os requisitos minimos de ordem legral.

$33 \mathrm{O}$ órgão regulacior analisará o estabelecimento de tarifas aeroportuárias regionais que incentivem este tratego. 3.4 Os órgãos de controle de fronteira deverâo simplificar os procedimentos, de forma a estimular e facilitar a circulaçâo do pessoas e bens na regiăo, podendo atuar diretamente ou mediante convênio. 3.5 Deycrá ser cstimulado o multilateralismo sul-americano como forma de integraçäo política, conômica e cultural da Arnerica do Sul mediante o aperfeiçoamento e ampliaçăo do "Acordo de Fortaleza" ou ontro acordo multilateral espectico.
} 
Curitiba e deixou na inércia - para não dizer que atuou contra - as oportunidades da integração e desenvolvimento da porção norte do estado. A melhor alternativa está, portanto, num modelo de complementaridade entre as duas principais cidades e na intermodalidade, já que a rivalidade e a busca de objetivo único no modal aéreo fragmentará o potencial da região.

Um aeroporto internacional moderno demanda investimentos e uma infra-estrutura aeroportuária privilegiada, com órgãos públicos especializados, tais como: Polícia Federal, para controle migratório; Receita Federal, para controle aduaneiro; Ministério da Saúde, para controle sanitário e Ministério da Agricultura, para controle fitossanitário. $\mathrm{O}$ processo de implantação de uma Estação Aduaneira do Interior (EADI) em Londrina será um ponto de apoio, caso haja compartilhamento com a implantação de um Terminal de Carga Aérea (TECA) no Aeroporto para o recebimento de mercadorias, averiguação de tributos e exportaçôes. Estas medidas estão na esfera do possivel e prometem catalisar a economia da região e ampliar a malha de negócios da região, favorecendo a intermodalidade e o desenvolvimento comercial e social.

Se a princípio a internacionalização do aeroporto, demanda os vário serviços públicos para o processamento de nacionalização mercadorias e passageiros. As burocracias exigidas, no âmbito do Mercosul, deverão ser reduzidas, já que este é o objetivo maior do Tratado de Assunção, bem como do Acordo de Fortaleza, que no artigo 10 prevê:

Cada Estado Parte empregará todos os esforços com vistas à máxima simplificação e compatibilização de suas normas e procedimentos relativos à facilitação do transporte aéreo Internacional (Imigratórios, Aduaneiros e de Vigilância Sanitária e Fitossanitária) nas operações sub-regionais, sem prejuízo do cumprimento das Normas de segurança da Aviação Civil Internacional.

Aliás, o Conselho Nacional de Aviação Civil (CONAC), presidido pelo ministro da Defesa, José Viegas Filho, aprovou 17 (dezessete) resoluções ligadas ao transporte aéreo. A mais importante para a integração regional é a de $n^{\circ}$ 004/2003, aprovada em 30 de outubro de 2003 , que no item terceiro prevê a utilização de aeroportos domésticos no tráfego regional internacional e, ainda, faz menção expressa a necessidade de aperfeiçoamento e ampliação do Acordo de Fortaleza. 
Com as últimas medidas do CONAC é possível que o Brasil reconheça a grande lição de Dr. Adyr da Silva, no livro Aeroportos e Desenvolvimento ${ }^{13}$;

$\mathrm{O}$ transporte rodoviário intenso está restrito às estradas pavimentadas e o transporte ferroviário às vias férreas. $O$ avião, ao contrário, desloca-se livremente pelos ares. Com ele, os obstáculos fisicos desaparecem e o uso do transporte áreo, cujo preço do serviço não demanda imensas fortunas, está presente para assegurar a comunicação, o apoio e a integração de qualquer que seja a localidade.

\section{Conclusão}

O modelo de integração aérea comunitário difere, radicalmente, do modelo adotado no Mercosul, na Comunidade Andina e na União Européia a integração é total, incluindo a cabotagem aérea, que elimina as restriçōes na operação dos serviços aéreos entre os Estados Membros. No Mercosul, a integração é parcial e não prevê a cabotagem aérea e nem uma desejada política comum dos transportes.

Contudo, apesar das críticas procedentes quanto as tímidas medidas tomadas em relação a liberação do modal aéreo, o Acordo de Fortaleza poderá ter seus objetivos maximizados no sentido de viabilizar a realização de novos serviços aéreos na sub-região e assim contribuir para reforçar e facilitar a integração entre os povos dos Estados Partes.

Ressalta-se, que só recentemente a Argentina aprovou o Acordo de Fortale$\mathrm{za}$, através da Lei $\mathrm{n}^{\circ} 25.806$, que foi sancionada em 05 de novembro de $2003 \mathrm{e}$ publicada em 28 de novembro de 2003. A ratificação pela Argentina dará uma nova perspectiva ao Acordo, pois se trata do maior parceiro comercial do Brasil no Mercosul, que compartilha os mesmos interesses na reciprocidade dos direitos de tráfego dos futuros serviços aéreos sub-regionais.

Ao observar o mapa do Mercosul, nota-se que a região Norte do Paraná está numa posição geográfica privilegiada, no centro do Mercosul, entre as principais regiões brasileiras, e no eixo entre o Atlântico e o Pacífico Chileno. As cidades no Norte do Paraná poderão ter uma conexão direta e rápida com o Norte da Argentina, Chile, Bolívia, Paraguai e Uruguai, viabilizando as conexões entre as microrregiões importantes que estão próximas entre si, longe das capitais e no interior do Mercosul. Aliás, uma da consequiência direta da liberalização dos direitos de tráfego 
na sub-região será o aumento das conexões transversais no eixo leste/ oeste, valorizando a interiorização do bloco, já que a predominante estrutura de conexôes longitudinais, no eixo norte/sul, representa um modelo ultrapassado da urbanização litorânea, na qual os países do continente davam-se as costas.

A consolidação da integração aérea do Norte do Paraná depende mais de aspectos políticos que da infra-estrutura ou de aspectos legais, pois há condições satisfatória para a promoção de um aeroporto internacional na região com um Terminal de Carga Aérea; demandando a vontade política no sentido de maximizar os recursos existentes e explorar as conquistas previstas no Acordo de Fortaleza.

\section{BIBLIOGRAFIA}

BRIANZA, Carlos Rodrigues. Balance 2003. Segunda Parte: la integración. AVIAGLOBAL: artigo, $30 \mathrm{dez}$. 2003. Disponivel em: <htpp:// www aviaglobal.com>. Acesso em 10 jan. 2004.

DA SILVA, Adyr. Aeroportos e Desenvolvimento. Rio de Janeiro: INCAER/ VILLA RICA, 1991.

FERREIRA, Luiz Antônio Félix. Transporte Aéreo Internacional: características, custos e visão de logística. São Paulo: Aduaneiras, 2003.

INSTITUTO DE AVIAÇÃO CIVIL. Estudo básico para a internacionalização de Aeroportos de apoio à aviação sub-regional no Mercosul. IAC, Rio de Janeiro: maio, 1999.

INSTITUTO DE PESQUISA ECONOMMICA APLICADA. Aspectos Institucionais e Regulatórios da Integração de Transporte do Mercosul. Texto para discussão $n^{\mathrm{a}}$ 444. CASTRO, Newton de; LAMY, Philippe. Rio de Janeiro, IPEA, 1996.

JURADO, Augustin Rodrigues (cord.).El MERCOSUL y el Transporte Aéreo. $1^{\circ}$ ed. Virtual. E-libro net. Septiembro, 2001.

QUINTAS, Helder; MARTINS, Amílcar. Direito dos Transportes: legislação nacional, internacional e comunitária - jurisprudência nacional e comunitária. Lisboa: Almedina, 2002.

RIBEIRO, Luciano R. Melo. Traçando os Caminhos dos Céus: O Departamento de Aviação Civil - DAC 1931 - 2001. Action Editora: Rio de Janeiro, 2002.

RODRIGUES, Gualdino. As fontes internacionais do Direito Aéreo: a situação da legislação sobre a aviação civil em Portugal. Lisboa: Dislivro, 2003. SILVEIRA, Expedito Albano da. A Globalização e os Acordos Bilaterais. SBDA: revista $\mathrm{n}^{\circ} 80$, Rio de Janeiro, 2000. Disponivel em: <htpp:// www.sbda.org.br>. Acesso em 10 jan. 2004. 